\title{
An Overview of Translation Practice in Odisha: From Transcreation to Translation
}

\author{
Sonali GANGULY*, Lipika DAS ${ }^{* *}$ and Tanutrushna PANIGRAHI***
}

The paper studies the historical evolution of translation tradition in an Indian provincial state, Odisha. The translation practice in Odisha projects an extensive history that enlists massive translations published since antiquity. The existing studies on the history of Odia translation focused either on the chronological development of Odia literature with an emphasis on translation or analyzed the socio-political matrix that prepared grounds for language movement and encouraged the literary development in Odia language. We argue that the study remains incomplete without a critical analysis of the trends, methods, strategies, and evolving discourses on translation that are not mutually exclusive. Changes were marked not only in the translation practice in distinct literary periods but also in the perception of the practitioners on defining translation. Exposure to world literature and Western concepts associated with translation practice enabled the Odia translators to examine practical problems and implement specific principles in their work. Nevertheless, the adopted strategies and principles were not blind adherence to Western concepts. We intend to examine the critical essays (nineteenth-twentieth century) reflecting the history, relevance, prevalent trends, principles, methods, and strategies of translation in Odisha. The thorough study redefines translation in Odisha from various perspectives. Furthermore, the paper analyzes the discourses on Odia translation from transcreation to adaptation, self-reliance to intertextuality. Keywords: translation; colonialism; history; Odia translation practice; adaptation; transcreation

\section{Introduction}

Translation has emerged in various forms since antiquity but has received attention as a discipline only in the recent past. As a practice, it persisted in almost every part of India, but the theories, propositions, and the crucial aspects of translation were never discussed prior to the

\footnotetext{
* PhDc at International Institute of Information Technology, Bhubaneswar. E-mail: c617001@iiit-bh.ac.in; ORCID ID: https://orcid.org/0000-0003-1493-9556.

** Assistant professor at International Institute of Information Technology, Bhubaneswar.

E-mail: lipika@iiit-bh.ac.in; ORCID ID: https://orcid.org/0000-0003-3048-9647.

*** Assistant professor at International Institute of Information Technology, Bhubaneswar.

E-mail: tanutrushna@iiit-bh.ac.in; ORCID ID: https://orcid.org/0000-0001-7639-5158.

(Received 3 April 2020; accepted 3 June 2020)
} 
transLogos 2020 Vol 3 Issue 1

Ganguly, Sonali, Lipika Das,

and Tanutrushna Panigrahi, pp. 46-69

trans Dogos

A Translation Studies Journal

An Overview of Translation Practice in Odisha:

From Transcreation to Translation

(C) Diye Global Communications diye.com.tr|diye@diye.com.tr

Western influence in the nineteenth-century India. The concept of translation has undergone a rapid change (both in the West and in the East) due to several factors such as cultural distinction, evolving theories and complexities, rejection, and criticism in the hands of experts such as Matthew Arnold, Virginia Woolf, Victor Hugo, Samuel Johnson, and many more. Resistance to all criticism, over time, has ultimately earned 'translation' the status of the most promising discipline that serves as a fulcrum in the study of world literature in the current century.

The paper intends to explore the translation tradition in Odisha and examine the principles and theories, particularly in Odia (native language of Odisha) translation literature. Odia is one of the Indo-Aryan languages of India spoken by $82 \%$ of the population in Odisha. It is also designated as the sixth Indian classical language based on a long literary history. This southeastern territory of India sets a perfect place to explore the emergence and evolution of translation tradition because of two major causes. First, the rich historical evidence certifies that the translation practice enhanced Odia literature. Second, the territory once housed multiple languages that threatened the existence of the native language, Odia. Translation served as a shield against the linguistic suppression and made a remarkable contribution to earning Odia a legalized status. Amidst severe political and linguistic turmoil, translation in this Indian province passed through several phases that redefined translation.

The term 'translation' literally means linguistic transference (Mahapatra [1982] 2018, 121). It is further defined as transference of meaning (Dhal [1953] 2018, 14), the exemplification of thoughts and emotions from a source language (SL) to a target language (TL). Encyclopaedia Britannica defines 'translation' as a process of "carrying over or transference from one to another" (Mishra 1998). Having a Latin origin, 'trans' means 'across' and 'latus' means 'to carry.' The two, together, refer to 'carry something.' The Odia equivalent is 'anuvaad' having a Sanskrit root. 'Anu' is a prefix that means 'later,' and 'vaad' means 'to speak' (Mishra 1998; Das 1999; Pradhan [2016] 2018, 245). 'Anuvaad,' in Sanskrit, is referred to as 'paschyatakathana' or 'punahakathana' (Das 1999; Pradhan [2016] 2018, 246), which mean 'to speak later' or 'repetition of the utterance,' respectively. The above-mentioned two Sanskrit terms do not shed light on the most crucial aspect of translation, i.e., language. However, if the Latin and Odia meanings are united, they form the 
transLogos 2020 Vol 3 Issue 1

Ganguly, Sonali, Lipika Das,

and Tanutrushna Panigrahi, pp. 46-69

trans Dogos

A Translation Studies Journal

An Overview of Translation Practice in Odisha:

From Transcreation to Translation

(C) Diye Global Communications diye.com.tr|diye@diye.com.tr

English term 'translation,' which means 'transference of meaning' or 'transference of essence of a literary work.' Translation is always a transition between two different language systems. The literal meaning of 'repetition' (punahakathana) is not 'translation,' as the latter is associated with several technical aspects. However, Sanskrit literature in translation of Veda, Upanishad, and other scriptures referred to translation as 'punahakathana' (repetition), 'punarabruti' (recitation), and 'paschyatakathana' (saying after). The definition of translation as 'imitation,' 'creative process,' 'transmission of the essence,' 'creative mode of literary expression,' 'tool against linguistic subjugation,' and 'a gateway to world literature' is the result of a response to the socio-cultural, political, and linguistic change and an ever-evolving perception towards translation based on literary practices over the ages.

The concept of translation is not recent to the literary consciousness of Odisha. It has existed since the fifteenth century, in the form of various translations of Sanskrit scriptures into Odia. The analytical study of translated pieces started not before the nineteenth century. So, the lack of theoretical framework posed the need to redefine translation and explore the inherent issues critically. The existing research in the history of Odia literature tended to shed light on different approaches adopted to study the development of literary periods (yugas) based on the literary contributions of the leading authors and translators. Aditya Kumar Panda (2017), in "Translation in Odia: A Historical Overview," surveyed major translated works in Odisha that reflected the chronological development of Odia literature through translation. He almost prepared a timeline of Odia literature that was enriched through translation over the ages and provided the glimpses of the prevalent methods of translation such as transcreation, adaptation, interpretation, retelling, and imitation (Panda 2017, 257). He demonstrated the changes in translation practice and categorized the history of Odia translation into four broad literary periods from the fifteenth century to the twenty-first century. The segmentation is based on the major translated works in each period. Further studies extended their scope to explore the significant role of translation in a politically scattered territory that ultimately formulated the state, Odisha. The colonial period represents the most crucial phase that brought changes in the perception and practice of translation in Odisha. Prof. Panchanan Mohanty and Dr. Ramesh Chandra Malik (2017), in "History of Odia Translations 
transLogos 2020 Vol 3 Issue 1

Ganguly, Sonali, Lipika Das,

and Tanutrushna Panigrahi, pp. 46-69

trans Logos

A Translation Studies Journal

An Overview of Translation Practice in Odisha:

From Transcreation to Translation

(C) Diye Global Communications diye.com.tr|diye@diye.com.tr

(1803-1936): A Bottom-Up Approach,” made an elaborate study on the socio-political, cultural, linguistic, and educational aspects that projected the multidimensional perspective of translation in colonial Odisha. The socio-political matrix dominates the discussion as a driving force that controlled the translation activities in the state. Thus, the study of Odia translation tradition is not only limited to the cultural and linguistic influences of Sanskrit, Bangla, and English, but the political agenda also played a significant role. The historical approach of Panda and the descriptive analysis of Mohanty and Malik illustrated the motivation and the issues that prompted, partially dominated, and nurtured the translation activities in Odisha. The discussions remained silent about the critical observations on the translated texts, which also evolved in Odisha. However, we find a passing reference to some techniques of translation followed by a remark on lack of theorization.

Sujit Mukherjee (1981), Samantak Das (2002), Ravi Kumar (2013), and Harish Trivedi (2004), in their respective works, acknowledged lack of sound theories in Indian translation tradition. Nevertheless, the Odia intelligentsia succeeded in identifying the 'evolution of translation' in Odia language from 'transcreation to transference' and 'adaptation to translation proper.' They attempted to define the responsibility of translators and devised a set of guidelines to be strictly followed. The formed strategies were not a blind imitation of the West, but a resultant of the critical analysis of the translation practice. The critics, authors, and translators in the twentieth-century Odisha used the literary magazines like Jhankar, Konark, Samalochana, Utkal Sahitya, Anuvaad Sahitya, and many more as the platform to discuss, analyze, and examine the literary pieces and evaluate the influence of the West on Odia translation literature. Editors and literary analysts such as Chittaranjan Das (1988), Sitakanta Mahapatra (1975), and Khageshwar Mahapatra ([1982] 2018), among many others, discussed the politics of Odia translation. Renowned scholars like Jatindra Kumar Nayak, Himanshu Mohapatra, Paul St-Pierre, and Panchanan Mohanty further analyzed the Odia translations of the Western texts and added new perspectives of translation in modern Odisha. They identified various translation techniques such as adaptation, manipulation, and reproduction of the source text (ST) with local colors through comparative analysis of STs and target texts (TTs). Shakuntala Balliyarsingh, the Sahitya Academy Award-winning contemporary Odia translator, made another remarkable initiation in this field of 
transLogos 2020 Vol 3 Issue 1

Ganguly, Sonali, Lipika Das,

and Tanutrushna Panigrahi, pp. 46-69

trans Dogos

An Overview of Translation Practice in Odisha:

A Translation Studies Journal

From Transcreation to Translation

(c) Diye Global Communications diye.com.tr|diye@diye.com.tr

study. She launched a literary magazine titled Satabhikhya on Odia translated literature in 1999. In the editorials of each edition, she commented on the importance of translation for enhancing Odia literature. These discourses on the principles of Odia translation practice added to the history and evolution of translation tradition in Odisha. In addition to that, Mohanty and Malik (2018) edited a compilation of more than twenty-five critical essays on discourses of Odia translation into a book titled Sanjoga Shilpa ra Sutradhaar: Odia Anuvaad Adhyayana ra Kramaparinama (Architect's craft of communication: A chronological history of the Odia translation studies). The book provides a chronological development and evolution of translation in Odisha. These critical essays adequately reflect on the history, relevance, and prevailing local trends of translation, the intricacies in the process, and the role and eligibility of a translator. The critical observation of the trends and principles in the essays not only projects the chronological development of translation tradition but also provides an insight into the challenges and complexities in Odia translation.

The paper intends to reexamine the history of Odia translation and argues that the study of the discourses of Odia translation serves as another important approach to the field of study. An elaborate discussion on the discourses of translation would make the study of Odia translation history complete. In this regard, this study examines the purpose, content, issues, strategies, influence, and relevance of translation in three literary periods that have created the history of Odia translation literature. The discussion takes into consideration critical perspectives based on secondary sources, such as the critical essays, prose pieces, and articles on translation published in various literary magazines in the twentieth century, to assess the evolving debates on Odia translation tradition over the ages. Furthermore, various perspectives towards translation are analyzed. For convenience, we have classified the translation tradition in Odisha broadly under three categories:

(i) Pre-colonial (fifteenth century-eighteenth century)

(ii) Colonial (nineteenth century-twentieth century)

(iii) Post-colonial (twentieth century-twenty-first century)

The pre-Sarala, the Panchasakha, and Bhanja periods are included in the pre-colonial period. The categorization of the periods may enlist the selective translations relevant to the 
transLogos 2020 Vol 3 Issue 1

Ganguly, Sonali, Lipika Das,

and Tanutrushna Panigrahi, pp. 46-69

trans Dogos

An Overview of Translation Practice in Odisha:

A Translation Studies Journal

From Transcreation to Translation

(C) Diye Global Communications diye.com.tr|diye@diye.com.tr

discussion and draw attention towards the distinct functions performed by translation in the diverse ages. Apparently, there have been different challenges and shifts in the strategies depending on the socio-political influence of each period on the purpose, content, and approach of translation in Odisha.

\section{Pre-Colonial Period}

Amid ample evidence of passing literary texts from Sanskrit to other Bhasas (native Indian languages) in India, including Odia, translation has a long history. In the pre-colonial era, lack of any specific translation theory in India led the translated texts to be considered as 'new writing.' Does it mean the original texts were lost? Or distortions and minor changes in the TTs were accepted? The critical analysis of the levels of adjustments and manipulations in the TTs would answer the posed questions.

The pre-colonial period was mostly influenced by Sanskrit literature. From the sixteenth century to the eighteenth century, the trend of Odia translation revolved around 'transcreation' of Sanskrit classics and religious scriptures, Puranas and Upanishads. This phase witnessed a paradigm shift in the medium of literary expression, i.e., transformation of the Sanskrit texts from the oral tradition to the written form. From the fifteenth century to the eighteenth century, Sanskrit served as the only donor language for around four hundred years that enriched almost all the vernacular languages of India, including Odia. Sixteenth to eighteenth-century translation dealt with the translation of ancient palm leaf writings into Odia. There are references to several translations or, more appropriately, 'transcreations' of the Sanskrit classics undertaken by the translators that made Sanskrit literature a life-giving force for Odia translation during this era. Such translation of Sanskrit classics into Odia started with Adikavi Sarala Das's (the father of Odia translation literature) transcreation of the epic Mahabharata in the fifteenth century (Panda 2017, 259; Pradhan [1959] 2018, 18). In this context, the concept of translation demands critical observation because the literary endeavor during this phase could not be considered as proper translation. Nilamani Mishra ([1976] 2018), an Odia literary critic, in his article "Odia Anuvaad: Sahitya O Purana" (Odia translation: Literature and Purana), analyzed the techniques used in Odia 
transLogos 2020 Vol 3 Issue 1

Ganguly, Sonali, Lipika Das,

and Tanutrushna Panigrahi, pp. 46-69

trans Logos

A Translation Studies Journal

An Overview of Translation Practice in Odisha:

From Transcreation to Translation

(c) Diye Global Communications diye.com.tr|diye@diye.com.tr

translation of the Mahabharata, the Ramayana, and Chandi Purana. Das retained only the name of major characters and events of the plot. He utilized individual liberty and considered the contemporary socio-political scenario and cultural and traditional mannerism of Odisha while rewriting the scripture into Odia. Mishra ([1976] 2018) further examined the plot that revolved around several instances of exaggerated supernatural interventions displaying the translator's imagination. He added colloquial words in his retelling of the Mahabharata, whereas Balram Das, in the following century, preferred free translation of the Ramayana. Das made it a loose translation or partial translation of the ST as he created new narratives in a few sections and deviated from the ST. In the sixteenth century, Jagannath Das's Odia Bhagavada earned popularity and projected manipulation of the ST. Das changed the chapterization of the ST and added new narratives. He used descriptive analysis at places to explain the philosophical essence of the ST. The techniques of addition and modification of the translated text and deviation from a literal translation prevailed in Odisha. The literary pieces rendered in the TLs received equal prominence as creative writing or new writing. Scholars termed it as 'transcreation' (Chaudhury 2015, 590). Mukherjee considers this creativity of translation as a mode to maintain proximity with the ST. In his words, translating a literary work is 'creative writing' that "stands very close and nearly equal to the [original] writing of it" (Mukherjee 2004, 38).

The seventeenth and eighteenth century flooded with the Odia translations of the Ramayana, the Mahabharata, and the Srimad Bhagavad Gita (Holy Gita) (Panda 2017, 260). Brudaban Das and Bajri Das translated the Sanskrit epic poem Geeta Govinda into Odia. Other epic poems that were translated during this phase were the Ramayana Champu, Amarusataka, Heetopodesha, Hansaduta, and Hamunannataka (Mishra [1976] 2018, 89). Translators used paraphrase and transformed the STs from poetic to prosaic form. Repeated translation of the same texts over the ages indicated the easy availability of the STs and no strict adherence to the concept of 'authorship' or 'copyright' during this phase. The literary texts were considered as a 'universal treasure of mankind,' open for anybody to use and rewrite. These renderings further hinted at the prevalent translation trends in Odisha (Das 1988). The translators followed an antagonistic approach in transcreating or rewriting the texts. At the beginning of the seventeenth century (Riti 
transLogos 2020 Vol 3 Issue 1

Ganguly, Sonali, Lipika Das,

and Tanutrushna Panigrahi, pp. 46-69

trans Dogos

A Translation Studies Journal

An Overview of Translation Practice in Odisha:

From Transcreation to Translation

(C) Diye Global Communications diye.com.tr|diye@diye.com.tr

Yuga of Odia literature), they attempted to establish parallelism in Odia language and literature by imitating the style of Sanskrit literature. They replaced simple verse with complex phrases, and the choice of words was ornamental and figurative.

Janakiballav Mohanty (1969) and Laxminarayan Mohanty (1971), in their respective essays, referred to the prevalence of 'bhasantara' or 'transmission from one language to the other' in the pre-colonial Odia translation. The two papers shared an identical title (i.e., "Odia Anuvaad Sahitya" [Odia translation literature]) and were published in Jhankar and Konark, respectively, in different years. However, the question whether the terms 'bhasantara' and 'transcreation' mean the same thing or they refer to two unique practices prevalent in Odisha arises. 'Bhasantara' means 'transference of ST into another language,' whereas the literal meaning of 'transcreation' is 'a creative piece of writing.' The former appears to be language-oriented, whereas the latter is textoriented or content-oriented. It is worth mentioning that the translators, then, were less concerned about the technicalities of translation; hence, 'transcreation' and 'bhasantara' in ancient Odia translation acted as synonyms (Rath [1921] 2018, 1). However, the thin line of distinction between 'translation' and 'transcreation' is exhibited well by Mohanty (2018) in the foreword of his coedited book on Odia discourses of translation titled Sanjoga Shilpa ra Sutradhaar: Odia Anuvaad Adhyayana ra Kramaparinama. He referred to the technicalities (equivalence, fidelity, readability) associated with the former to state differences. For instance, Guru Prasad Mohanty referred to T. S. Eliot's The Waste Land while writing Kalapurusha; however, the piece was not a translation but a transcreation.

The discourses on the pre-colonial translation practice in Odisha reveal the inherent purpose of translation that determined the translation strategy. Translation in the pre-colonial Odisha revolved around Sanskrit literature. The purpose was not favoritism for any religion but to eradicate the command of the Brahmin (a particular elite class) who read the scriptures in Sanskrit. Limited access of common public to Sanskrit scriptures confined literature to being a treasure of the Brahmins and encouraged the translators to target the religious scriptures for translation into Odia. The oral tradition and the Sanskrit script guided the retellings of the religious scriptures. These retellings were further influenced by the contemporary socio-political, linguistic, behavioral, and 
transLogos 2020 Vol 3 Issue 1

Ganguly, Sonali, Lipika Das,

and Tanutrushna Panigrahi, pp. 46-69

trans Dogos

A Translation Studies Journal

An Overview of Translation Practice in Odisha:

From Transcreation to Translation

(C) Diye Global Communications diye.com.tr|diye@diye.com.tr

cultural stance of Odisha. The transcreations acted as 'a liberating force' that made the literary texts available to the native readers in their mother tongue (irrespective of caste), free from the hegemonic grip of the 'so-called' only language of literary expression, i.e., Sanskrit. It was for the first time that the ancient epics, epic poetry, lyrical poetry, scriptures, Puranas, Upanishads were considered something more than 'holy books,' a literary treasure that could be rewritten in Odia and read by the ordinary people. The translators emphasized more on readability and retained the essence of STs in the new writings. Nevertheless, free translation, new narratives, addition, deletion, and adaptation persisted, and the TTs received equal value as the STs till the nineteenth century. The individual liberty of the translator in rendering the ST was neither questioned nor even considered technically wrong. Mishra ([1976] 2018), in his essay "Odia Anuvaad: Sahitya O Purana," critically examined individual liberty in translating the Ramayana and the Srimad Bhagavad Gita into Odia. He claimed that the Sarala Ramayana (Ramayana by Sarala Das) in Odia is not equivalent to the original text. Even though the events and characters remained unchanged, a close reading of the text manifested the contemporary socio-political, cultural reflection of Odisha in his Ramayana, Mahabharata, and Chandi Purana (Mishra [1976] 2018). We name this technique of 'individual re-appropriation of the Indian tradition and ancient scriptures in Odia translation' as 'chhayanuvaad' (adumbration). The TT is the reflection (chhaya) of the ST that retains its originality and overshadows a few sections of the ST. The translators implemented translation as a medium of expressing their concern towards the contemporary societal practices.

Another important aspect of traditional translation practice in Odisha was the response to the concept of equivalence. A sharp distinction with the Western concept of equivalence was evident in Odisha translation practice. The traditional Indian translation aimed at the attainment of equivalence in terms of the emotional impact of the text. The semantic resemblance scarcely gained attention until the post-war period in the nineteenth century. Mini Chandran (2016) argued that the phase was mostly guided by the Indian theories of aesthetics that prompted the translators to attain equivalence in terms of rasa and dhvani theories of Indian poetics, accounting for the emotional impact of the TT on the readers. Furthermore, the loss and gain in translation was never discussed 
transLogos 2020 Vol 3 Issue 1

Ganguly, Sonali, Lipika Das,

and Tanutrushna Panigrahi, pp. 46-69

trans Dogos

An Overview of Translation Practice in Odisha:

A Translation Studies Journal

From Transcreation to Translation

(C) Diye Global Communications diye.com.tr|diye@diye.com.tr

until the nineteenth century in Odisha. Overall, the conception of 'translation' inclusive of fidelity and equivalence is the result of a colonial perception, which is elaborated on in the subsequent section.

\section{Colonial Period}

Colonialism and advent of English language influenced the translation tradition in India (Odisha was not an exception), which brought a paradigm shift in the translation practice. As stated by Mukherjee $(2002,26)$, "[w]ith the advent of English, the context and role of translation in India changed radically" (quoted in Di Giovanni 2013, 104).

English, in the colonial period, became the dominating language of literary expression but could not displace Sanskrit from the royal status. The year 1803 announced a new beginning with the advent of the printing press, which replaced the palm leaf tradition. The Christian missionaries introduced a new tradition of translation in Odisha through Bible translation in 1814 (Panda 2017, 262). Preaching Christianity was their primary objective behind translation, publication, and circulation of the Bible in Odia language. Bible translation brought with it the concept of 'fidelity.' The translators were strictly instructed to adhere to the 'word of God'; any distortion to it was not commendable. The inherent politics was to restrict the translators from being influenced by the free translation practice (prevalent in Odisha) that might represent the Bible with 'distortion of the real meaning.' Prioritizing the notion of fidelity and equivalence of the meaning, in the later years, was considered as a 'Western metaphysical obsession' by Ganesh N. Devy (1995, 149). Shantha Ramakrishna further explains the influence of the Western concepts and theories of translation on the Indian tradition. In his words,

Indian translators have not traditionally been preoccupied with the question of fidelity; adaptations were and still continue to be quite common. Whereas in the past such adaptations were well received and welcomed by readers as important contributions to the development of language and literature, the modern-day translator and his bilingual critic often attach undue importance to the question of fidelity. (Ramakrishna 2002, 87)

The period from 1803 to 1870 witnessed massive translation from English to Odia that introduced English literature to British colonies. English took over as a master language that 
transLogos 2020 Vol 3 Issue 1

Ganguly, Sonali, Lipika Das,

and Tanutrushna Panigrahi, pp. 46-69

trans Dogos

A Translation Studies Journal

An Overview of Translation Practice in Odisha:

From Transcreation to Translation

(C) Diye Global Communications diye.com.tr|diye@diye.com.tr

controlled the entire translation circuit. Nevertheless, Sanskrit continued to be the SL of translation into English. Odia literature was yet to find its place in the literary market, but the final phase of the nineteenth century witnessed a rise in the Odia literary consciousness. Initiatives were made by the Odia intelligentsia to respond to the need of time.

Translation trends during this phase could be classified into two categories based on the flow of translation: (i) translation from Sanskrit to English, (ii) translation from English to Odia (and other Indian languages). The British focused on ancient Sanskrit literature, rich with traditional Indian values, for translation. The objective was to understand the Indian sentiment for administrative purposes. This was the period of 'influence.' The initial transaction between Indian and Western literature was through the translation of Sanskrit literature that exerted a huge literary influence on the West in the mid-nineteenth century (Trivedi 2007, 121). A long list of Sanskrit texts was translated into English, among which the Western readers appreciated Kalidasa's Abhijanashakuntalum (Shakuntala) most. The current study is concerned with the second mode of translation (English to Odia), which needs to be analyzed through a socio-political perspective.

Odisha in the nineteenth century was bearing with double-colonialism: politically in the hands of the colonizers, culturally and linguistically in the hands of the dominating languages of the neighboring states. The politically dismembered Odia-speaking territory was scattered virtually across the presidencies of Bengal, Bihar, Madras, and Central Province, which reduced the status of Odia to a linguistic minority. It witnessed the linguistic discrimination, social and cultural subjugation, and the threat of detachment of Odia language from academics and administration based on the arguments such as lack of books available in Odia for primary education and the need of the fragmented territory to adopt the language of opportunity for educational and administrative purposes. Meanwhile, the publication of the book titled Odia Ekti Bhasha Noye (Odia is not a language) by Kantichandra Bhattacharya that claimed Odia as a variant of Bangla (Acharya 2016, 27-33; Mohanty 2002, 55; Barik 2006, 5-6), the proposal to replace Odia with Bangla as the official language by Rajendralal Mitra, and the suggestion to adopt the Bangla script for Odia writing by Umacharan Haldar created havoc (Patnaik 2002, 3). Later, the administrative problems in the four different presidencies were planned to be dealt with by displacing the language, Odia. 
transLogos 2020 Vol 3 Issue 1

Ganguly, Sonali, Lipika Das,

and Tanutrushna Panigrahi, pp. 46-69

trans Dogos

An Overview of Translation Practice in Odisha:

A Translation Studies Journal

From Transcreation to Translation

(c) Diye Global Communications diye.com.tr|diye@diye.com.tr

The identity crisis of Odia as a language took a rebellious turn in the colonial period when the language was virtually on the verge of extinction. The consciousness regarding the linguistic colonialism generated the interest of the intellectuals in promoting Odia literature to restore territorial integrity. Odisha was both linguistically and politically prepared to legitimize the language by enriching Odia literature through the translation of Anglophone literature into Odia. Fakir Mohan Senapati, Radhanath Ray, Khirodchandra Raychoudhury, Bichandacharan Pattnayak, Jagmohan Lala, Sitanath Ray, Govinda Pattnayak, and Madhusudan Rao served as the pillars and expanded the literary horizon of Odia literature. They adapted foreign literary models and manipulated texts to retain individuality.

Translators continued to translate from Sanskrit literature and simultaneously turned towards the West in search of new forms and techniques of translation. Imitation and adaptation became preferred techniques during this phase. The growing influence of Western literature was reflected in the works of the two most influential translators of the era, Radhanath Ray and Nilakantha Das. Nevertheless, they maintained their individuality while translating the STs and deviated from the traditional translation procedure (Panda 2017, 263; Mishra 1998; Tripathy [1984] 2018, 135). Ray introduced blank verse to Odia and adapted several Sanskrit and English literary pieces. There are glimpses of Greek mythological stories, elements of Ovid's stories, and William Morris's Atlanta's Race in some of his writings. He adapted the style or the storyline in creating new literary pieces in Odia. His Chandrabhaga and Nandikeshwari are the imitations of Ovid's Metamorphoses. The plot construction and character sketch of his literary piece Parvati reflected the imitation and adaptation of Greek and English plays. Das, a renowned translator and author of Satyabadi era, wrote Dasa Nayaka, an adaptation of Alfred Tennyson's Enoch Arden, and Pranayini, a translation of The Princess (Mohanty 1971). Kumudini Mishra in 1998 perceived Das's translation skills in making the author visible in the TT. Mishra made a comparative study of the original and the translated version on the basis of qualitative and contextual equivalence. She confirmed the retention of the ST essence but Odianization of the characters, names, and places. In the foreword, Das stated the objective of translation. In his words, "Not all literary pieces are meant for adaptation. A perfect selection of a text that could be reshaped and rewritten without 
transLogos 2020 Vol 3 Issue 1

Ganguly, Sonali, Lipika Das,

and Tanutrushna Panigrahi, pp. 46-69

trans Logos

An Overview of Translation Practice in Odisha:

A Translation Studies Journal

From Transcreation to Translation

(C) Diye Global Communications diye.com.tr|diye@diye.com.tr

losing the original essence, tone, and flow is the success of translation" (quoted in Mishra 1998; our translation).

The statement implicitly hinted at the sown seeds of 'untranslatability.' Later, Kunjabihari Tripathy's thematic analysis of Dasa Nayaka discovered the local pictures in Das's writing that enriched the local literature. Adaptation of selected aspects of the ST made the translation more lively and real.

History of Odia translation confirms the prevalent practice of poetry translation in the Odia tradition. A good number of lyric poems and epic poems have been translated from Sanskrit to Odia that prompted Dasarathi Das and Chintamani Behera to discuss the complexities in translating poetry. Das (1972), in his essay "Kavyanuvaad" (Poetry translation), projected an overview of poetry translation in the form of two schools of thoughts on 'translatability and untranslatability of poetry' by referring to Western theories and the Eastern practice. He viewed that the difficulty is not in 'what' but in 'how' of poetry translation. As meaning and words are not separate entities in poetry, the problem lies in expressing the same meaning with or without a change in the words (Bradley quoted in Das 1972). It is not the 'word-to-word' or 'verse-to-verse' translation but the 'ability to hear the inner voice of the poet' (Forster quoted in Das 1972) that solves the insoluble problem, i.e., translating 'poesie to poesie.' Behera ([1982] 2018) extended the discussion to analyze the evolution of translation practice and changes adopted over the years in poetry translation in his article titled "Kabita ra Bhasantara ra Prasanga" (On translating poetry). Behera asserted the significant role of the translator in establishing a proximity with the author and balancing the translation of word and sense, sound and rhythm, images and symbol to accomplish the expected outcome, i.e., 'creative transposition,' as stated by Roman Jakobson (Mohanty [1997] 2018, 151). Jagannath Prasad Das ([2006] 2018) sensed the complexity of translating lyric poetry, i.e., the synchronization between meter, rhythm, imagery, humor, and aesthetics in translation from language 1 (L1) to language 2 (L2). The critics did not elaborate the techniques of poetry translation in either of the essays but asserted that the problems of poetry translations could be dealt with by developing proximity with the poet by understanding the essence of poetry. The technicalities can be compromised without distortion of the meaning and essence. 
transLogos 2020 Vol 3 Issue 1

Ganguly, Sonali, Lipika Das,

and Tanutrushna Panigrahi, pp. 46-69

trans Dogos

A Translation Studies Journal

An Overview of Translation Practice in Odisha:

From Transcreation to Translation

(C) Diye Global Communications diye.com.tr|diye@diye.com.tr

Translation from Sanskrit literature and adaptation of literary works from Western literature moved hand in hand during the nineteenth century. Translation tradition in colonial Odisha was inclined towards the adoption of new techniques and strategies from the other world traditions. Saratchandra Pradhan ([1959] 2018), in his article "Odia Sahitya re Anuvaad" (Translation in Odia literature), emphasized on the three methods of translation prevalent during the colonial phase: (i) complete translation, (ii) adaptation, and (iii) poetry translation. The nineteenth and twentiethcentury translators preferred 'adaptation' and 'imitation' rather than transcreation. Nevertheless, the latter continued as a technique but was not free from the debate on fidelity and equivalence.

Translation during this phase was referred to as 'bhavanuvaad' by the literary experts (Pradhan [1959] 2018; Mohanty 1969). It retained the ST meaning and passages by using other words, which appeared similar to the technique of paraphrase. Paraphrase in Greek means 'additional manner of expression.' Paraphrasing and 'bhavanuvaad' were not considered as separate entities in Odisha, as the translated texts were 'bhava ra anuvaad' (translation of essence). In this technique, the literality of words, phrases, and expressions was an ignorable aspect, and the accurate display of the ST essence received priority. Translators used 'bhavanuvaad' to avoid repetition of certain words and structures and reduce the ST. They considered the context or situation in which the translation took place before determining the technique or method. The critics and experts like Khetrabasi Nayak ([1976] 2018), Rameshchandra Das (1999), Prafulla Kumar Mohanty ([2006] 2018), Dasarathi Das (1972), and Abhinnachandra Sahu ([1962] 2018) analyzed the Odia translations of the period and determined the following issues:

(i) The cultural and linguistic distinction between the SL and the TL posed the major challenge in the process.

(ii) Word-to-word rendering leads to incomplete or sometimes weird translation. The emphasis should be on the meaning or the essence.

(iii) Equivalence, fluency, and readability represent the three pillars of translation that made translation effective.

(iv) Translation problems differ according to the genre and target audience. For instance, translating poetry appears more difficult than fiction. The cultural and linguistic aspects become 
transLogos 2020 Vol 3 Issue 1

Ganguly, Sonali, Lipika Das,

and Tanutrushna Panigrahi, pp. 46-69

trans Dogos

An Overview of Translation Practice in Odisha:

A Translation Studies Journal

From Transcreation to Translation

(C) Diye Global Communications diye.com.tr|diye@diye.com.tr

challenging in fiction, whereas the synchronization between sound, rhythm, words and meaning in poetry makes it untranslatable to a greater extent. The translator has to be extra cautious while rewriting the ST for a young reader keeping in mind the acceptability, background knowledge, and age of the target reader.

(v) Lack of equivalent words in the TL is an inescapable issue of translation.

(vi) The individual liberty of the translator or the strict adherence to the ST remained a debatable topic ever.

(vii) Manipulation of the text dragged the readers away from the author and the ST.

Some of the posed issues made translation a vulnerable and secondary activity, in the Western perception, which, of course, was a partial view of the discipline. The critics further focused on the role of the translator in making translation effective and reliable. The debate on the significant contribution of the translator as a mediator was well observed in the works of Golokbihari Dhal ([1953] 2018), Janakiballav Mohanty (1969), Khetrabasi Nayak ([1976] 2018), Chintamani Behera ([1982] 2018), and Sourendra Barik ([2000] 2018), who suggested the following criteria:

(i) As a literary agent, the translator should develop proximity with the author.

(ii) Linguistic competence in both the SL and the TL is a must.

(iii) The translator should be more watchful towards the use of 'equivalents' in the TL to avoid 'distortion of sense or meaning.'

(iv) The translator should have a pre-knowledge regarding the target readers and their receptivity.

(v) Accuracy in expressing the ST in the TL is to be maintained (word choice).

(vi) A translator has to be a sensitive reader, an interpreter, and finally a creator.

Consistent development and evolution of translation in the nineteenth-twentieth-century Odisha negated the impression of translation as a 'sin' or 'reflection of the faded reality.' Authors such as Chittaranjan Das, Golokbihari Dhal, and Shakuntala Balliyarsingh and other practitioners attempted to redefine translation. Das (1988) considered translation as a practice that extended the literary horizon of the readers and brought them closer to the literature of the world. The universal 
transLogos 2020 Vol 3 Issue 1

Ganguly, Sonali, Lipika Das,

and Tanutrushna Panigrahi, pp. 46-69

trans Dogos

An Overview of Translation Practice in Odisha:

A Translation Studies Journal

From Transcreation to Translation

(C) Diye Global Communications diye.com.tr|diye@diye.com.tr

nature of literature was accomplished through translation and wide circulation towards the end of the twentieth century. Dhal ([1953] 2018) perceived translation as an 'international problem' which can be treated through 'an ideal translation' (17) whereas Balliyarsingh ([2006] 2018) considered translation as "universal connectivity with an eternal message of unification and humanism to the world" (213; our translation).

Translation in the colonial period acted as a tool against linguistic suppression that freed Odisha from the linguistic imperialism and legalized the status of Odia as a language. The translations proved the strength of Odia as a medium of literary expression and further led to the unification of the territory.

\section{Post-Colonial Period}

Post-independent Odisha was free from linguistic suppression and served as a platform to examine the further possibilities of translation. With a strong linguistic background and matured perception towards translation, the literary consciousness in the mid-twentieth century headed towards world literature. In response to the increasing literary consciousness towards world literature, Prafulla Kumar Das, a renowned Odia translator and the proprietor of Prafulla Press, made a remarkable venture of translating works of the Nobel laureates in Odia. Under his initiative, the literary pieces of Pearl S. Buck, George Bernard Shaw, Romain Rolland, Selma Lagerlöf, Grazia Deledda, Albert Camus, and Rabindranath Tagore were translated into Odia. It is worth mentioning that the first Asian translation of Boris Pasternak's epic novel Doctor Zhivago was made in Odia language (Mohanty 1971). Odisha book market was flooded with the cosmopolitan flavor of translated books from across the globe. Manmohan Press published Odia translations of literary pieces by the world authors like Kalidasa, Bhabvabhuti, William Shakespeare, Charles Dickens, Leo Tolstoy, Ezra Pound, Guy de Maupassant, Munshi Premchand, Arthur Conan Doyle, Anton Chekhov, Mulk Raj Anand, and many more. Mohanty (1971) extensively discussed the crucial role of translation in promoting world literature in Odia in his essay "Odia Anuvaad Sahitya." Mohanty perceived translation as a positive approach towards the accomplishment of mutual understanding, world peace through literary universalism. The period identified the 
transLogos 2020 Vol 3 Issue 1

Ganguly, Sonali, Lipika Das,

and Tanutrushna Panigrahi, pp. 46-69

trans Dogos

A Translation Studies Journal

An Overview of Translation Practice in Odisha:

From Transcreation to Translation

(C) Diye Global Communications diye.com.tr|diye@diye.com.tr

translators as the mediators between the diverse world cultures and world languages. This literary consciousness towards world literature was reflected in the contents of the literary magazines like Jhumuka and Utkal Sahitya. A separate section of the magazines contained the Odia translations of Western literature. In 1969, Granthamandir, a renowned Indian publication house, launched a World Literature Series titled Biswa Sahitya Granthamala (Collection of world literary texts) that introduced the world authors like William Shakespeare, Kalidasa, Jane Austen, Thomas Hardy, Homer, Anna Sewell, Arthur Conan Doyle, Robert Michael Ballantyne, Charles Dickens, Jonathan Swift, and many more along with the diverse world culture to the native readers in Odia translation.

Translation in this period performed a significant role in the cross-cultural literary exchange in an international forum. The emerging debates, during this period, focused on the importance of translation and put less emphasis on the translation principles. As the texts were expected to meet the international expectations, the translators imbibed the Western strategies and techniques. Mohanty ([2006] 2018), in his essay “Anuvaadaka ra Jantrana” (The translator's pain), highlighted the importance of translation, especially in the globally advanced twenty-first century. Translation might be a falsification or a faded image of reality, but it is a mandate for the circulation of literature in the world market. Mohanty asserted the importance of English translation for wider circulation, whereas Balliyarsingh ([2006] 2018) advocated Odia translation of the world texts. Das ([2006] 2018), in his article "Kabita ra Anuvaad" (Poetry translation), clarified the necessity to rely upon English translation. In his words,

English translation makes the literary texts eligible to cross the boundary of origin, not only in the international forum but also within the other regions of India. So, in a multilingual nation like India, translation, especially in the English language, is needed to preserve the literary treasure and make it available nationwide. (Das [2006] 2018, 205; our translation)

However, they seem to overlook the other side, which leads to the translation of all pieces of literature into a single global language, leading to monolingualism that distorts the real essence of world literature. In this context, Mahapatra (1975) expressed his concern, in his essay "Srujanashila Sahitya ra Anuvaad" (Translation of creative literature), and criticized the contemporary trend of translation in India. He regretted over the 'psychological malaise' of the Odia translators who remained indifferent towards Bhasa literature and inclined towards English. 
transLogos 2020 Vol 3 Issue 1

Ganguly, Sonali, Lipika Das,

and Tanutrushna Panigrahi, pp. 46-69

trans Dogos

A Translation Studies Journal

An Overview of Translation Practice in Odisha:

From Transcreation to Translation

(C) Diye Global Communications diye.com.tr|diye@diye.com.tr

The politics of language was evident in the perpetual growth of English translation that pushed the other Bhasa literature to the periphery.

The modern translation techniques relied on developing the author's perspective, realizing the essence and meaning before rendering into another language with a similar tone and pace. Balliyarsingh ([2006] 2018), in her essay "Anuvaad Kala: Samarthya O Sambhabana” (Art of translation: Competence and possibility), provided a deep insight into the complex socio-linguistic issues in translating Chinua Achebe's Things Fall Apart and the psychological struggle in Samuel Beckett's Waiting for Godot. She asserted the importance of developing proximity with the sociocultural background and the political scenario of the ST when it was published to balance the cultural and linguistic diversity. Translation turned to a profession during this period which made the experts and practitioners conscious regarding their role and emphasized on translator training.

Translation in the modern day appears to be the gateway to the international market and the worldwide reception of the literary treasure. Responding to the growing inclination towards world literature, the government and private organizations, institutes, and publishing houses joined hands with the translators in promoting translation activities. Odisha Sahitya Academy and National Book Trust promoted the translation of Odia literature into English and vice versa (Panda 2017, 269). Grassroots Publishing, Oxford University Press, and University of California Press are some of the noteworthy publishing houses that published the English translations of Odia literary works. Fakir Mohan Senapati's Chha mana Atha Guntha (Six Acres and a Third) and Gopinath Mohanty's Paraja made way to world literature during this phase through English translations by Rabi Shakar Mishra, Satya P. Mohanty, Paul St-Pierre, Jatindra N. Nayak, and Bijay Kumar Das, respectively. Later, massive translations of Western literary pieces by the world authors were published that included Thomas Carlyle's The Hero and Hero Worship, Samuel Richardson's Pamela, Fyodor Dostoevsky's Crime and Punishment, Herman Melville's Moby Dick, Pearl S. Buck's The Hidden Flower, and so on. 
transLogos 2020 Vol 3 Issue 1

Ganguly, Sonali, Lipika Das,

and Tanutrushna Panigrahi, pp. 46-69

trans Logos

An Overview of Translation Practice in Odisha:

A Translation Studies Journal

From Transcreation to Translation

(c) Diye Global Communications diye.com.tr|diye@diye.com.tr

\section{Redefining Translation in Odisha}

The elongated discussion above gives insight into 'what,' 'how,' and 'why' of translation in Odisha. It is evident from the above discussion that the definition of translation is not static. The changes evolved based on multiple functions it performed in different literary periods in Odisha. Earlier, translation referred to transference (bhasantara). However, close observation of the significant contribution of translation in preserving ancient literary texts, nation-building, and safeguarding vernacular languages reveals that translation is something beyond mere 'transference.' The multiple functions performed by translation in Odisha in different literary periods redefined translation from various perspectives enlisted below:

(i) Historical perspective: Translation is a means to preserve the ancient literary texts by transcreating, adapting, or literally translating into modern world languages, whereas the definition may vary when it comes to practice.

(ii) Linguistic perspective: Translation serves as a way to standardize language, empower vernaculars.

(iii) Cultural perspective: Translation is a link between diverse world cultures.

(iv) National perspective: Translation is a tool against linguistic suppression, a means of literary awareness and nation-building.

(v) Colonial perspective: Translation is a means of forceful subjugation of minor languages, claiming supremacy of the language of the colonizers.

(vi) Post-colonial perspective: Translation is a medium of self-recognition and a gateway to the world literary forum.

(vii) International perspective: Translation is a model of cross-cultural exchange of literary treasure.

The perception of translation techniques (fidelity and equivalence) was the consequence of the Western intervention. It is worth mentioning that the individuality of the translators did not die in the flow of new adoptions. The Odia translators did not surrender to any hegemonic oppression and retained their individuality. However, the translators were not reluctant to adopt the emerging concepts and methods of translation that added new dimensions to the literary tradition in Odisha. 
transLogos 2020 Vol 3 Issue 1

Ganguly, Sonali, Lipika Das,

and Tanutrushna Panigrahi, pp. 46-69

trans Dogos

A Translation Studies Journal

An Overview of Translation Practice in Odisha:

From Transcreation to Translation

(C) Diye Global Communications diye.com.tr|diye@diye.com.tr

The Western text, form, and techniques are adapted to showcase the strength of the native language. Furthermore, the hegemonic stance of Western literature could not replace Sanskrit completely; it continues to be the ST. The act of returning to the rich ancient literature in the post-independent era is considered as 'resistance to the Western values' and 'reassessment of the self' (Trivedi 2007).

\section{Conclusion}

The study implies that the practice of translation in Odisha was a struggle for self-identity and recognition. In the pre-colonial phase, the struggle was to withstand the Sanskritic influence on literary development. The practitioners were engaged in preserving the ancient literary treasure in regional language. Adaptations and modifications were identified later in the Odia translations. The objective was never to theorize as those writings were not considered as appropriations or retellings. Those were referred to as creative writings, i.e., original works rather than translations. The colonial era witnessed a master-slave relationship between the ST and the TT. Translation, during this phase, was subtly guided by the political and linguistic struggle. The fight for the legitimization of the native language resulted in the translators' shifting interest from traditional transcreation to the adoption of the techniques and forms. Western translation theories kept banging the literary zone, proving no space to theorize. However, attempts were made to analyze and elaborate on the principles and strategies of translation in post-colonial Odisha. The post-colonial era witnessed the perpetual growth of cross-cultural literary transaction and adoption of Western principles and models. These shifts were not a blind adherence to the Western concepts but an adequate response to the need of the hour. The discourses on translation practice in Odisha provided a quality assessment of the translated texts. We believe that the discussion on the translation tradition would have remained incomplete without discussing the debates on translation in Odisha since the early nineteenth century. We would conclude by referring to the hypothesis framed at the beginning about the existing critical observations on the Odia translation practice. The analysis of the principles, methods, and stylistic variations of the ancient and modern Odia translation elucidates that the rich literary treasure and the discourses on translation, together, redefine the function of translation in Odia literature. 
transLogos 2020 Vol 3 Issue 1

Ganguly, Sonali, Lipika Das,

and Tanutrushna Panigrahi, pp. 46-69

An Overview of Translation Practice in Odisha:

From Transcreation to Translation

transDogos

A Translation Studies Journal

(C) Diye Global Communications diye.com.tr|diye@diye.com.tr

\section{References}

Acharya, Snigdha. 2016. "Linguistic Movement of Odisha: A Brief Survey of Historiography." Odisha Review (April): 27-33. http://magazines.odisha.gov.in/Orissareview/2016/April/Aprilreview.htm.

Balliyarsingh, Shakuntala. (2006) 2018. "Anuvaad Kala: Samarthya O Sambhabana." [Art of translation: Competence and possibility.] In Sanjoga Shilpa ra Sutradhaar: Odia Anuvaad Adhyayana ra Kramaparinama [Architect's craft of communication: A chronological history of the Odia translation studies], edited by Panchanan Mohanty and Ramesh Chandra Malik, 213-218. Cuttack: Friends.

Barik, Pabitra Mohan. 2006. “A Movement for Restoration of Oriya Language.” Orissa Review (April): 5-6. http://magazines.odisha.gov.in/Orissareview/April2006/aprilreview.htm.

Barik, Sourendra. (2000) 2018. “Anuvaad Sapkarka re.” [About translation.] In Sanjoga Shilpa ra Sutradhaar: Odia Anuvaad Adhyayana ra Kramaparinama [Architect's craft of communication: A chronological history of the Odia translation studies], edited by Panchanan Mohanty and Ramesh Chandra Malik, 187-191. Cuttack: Friends.

Behera, Chintamani. (1982) 2018. "Kabita ra Bhasantara ra Prasanga.” [On translating poetry.] In Sanjoga Shilpa ra Sutradhaar: Odia Anuvaad Adhyayana ra Kramaparinama [Architect's craft of communication: A chronological history of the Odia translation studies], edited by Panchanan Mohanty and Ramesh Chandra Malik, 114-120. Cuttack: Friends.

Chandran, Mini. 2016. "The Practice of Translation in India." Sahapedia. November 1. Accessed May 21, 2020. https://www.sahapedia.org/the-practice-of-translation-india.

Chaudhury, Bijay. 2015. Odia Sahityara Sankhepa Aakalana [A brief analysis of Odia literature]. Cuttack: Chinmaya Prakashan.

Das, Chittaranjan. 1988. “Odia Anuvaad Sahitya: Eka Samikhya.” [Odia translation literature: An analysis.] Konark, no. 66.

Das, Dasarathi. 1972. “Kavyanuvaad.” [Poetry translation.] Jhankar 13 (11).

Das, Jagannath Prasad. (2006) 2018. "Kabita ra Anuvaad." [Poetry translation.] In Sanjoga Shilpa ra Sutradhaar: Odia Anuvaad Adhyayana ra Kramaparinama [Architect's craft of communication: A chronological history of the Odia translation studies], edited by Panchanan Mohanty and Ramesh Chandra Malik, 200-205. Cuttack: Friends.

Das, Rameshchandra. 1999. "Pilanka pae Anuvaad Rachana." [Translation for children.] Konark, no. 112 . 
transLogos 2020 Vol 3 Issue 1

Ganguly, Sonali, Lipika Das,

and Tanutrushna Panigrahi, pp. 46-69

An Overview of Translation Practice in Odisha:

trans Logos

A Translation Studies Journal

From Transcreation to Translation

(C) Diye Global Communications diye.com.tr|diye@diye.com.tr

Das, Samantak. 2002. "Multiple Identities: Notes towards a Sociology of Translation." In Translation, Text and Theory: The Paradigm of India, edited by Rukmini Bhaya Nair, 3545. New Delhi: Sage.

Devy, Ganesh N. 1995. In Another Tongue: Essays on Indian English Literature. Madras: Macmillan.

Dhal, Golokbihari. (1953) 2018. “Anuvaad.” [Translation.] In Sanjoga Shilpa ra Sutradhaar: Odia Anuvaad Adhyayana ra Kramaparinama [Architect's craft of communication: A chronological history of the Odia translation studies], edited by Panchanan Mohanty and Ramesh Chandra Malik, 12-17. Cuttack: Friends.

Di Giovanni, Elena. 2013. "Translation as Craft, as Recovery, as the Life and Afterlife of a Text: Sujit Mukherjee on Translation in India." TranscUlturAl 5 (1-2): 99-115. doi:10.21992/T9B325.

Kumar, Ravi, ed. 2013. Role of Translation in Nation Building. New Delhi: Modlingua.

Mahapatra, Khageshwar. (1982) 2018. "Sahitya re Anuvaad Samasya." [Literature and problems of translation.] In Sanjoga Shilpa ra Sutradhaar: Odia Anuvaad Adhyayana ra Kramaparinama [Architect's craft of communication: A chronological history of the Odia translation studies], edited by Panchanan Mohanty and Ramesh Chandra Malik, 121-128. Cuttack: Friends.

Mahapatra, Sitakanta. 1975. "Srujanashila Sahitya ra Anuvaad." [Translation of creative literature.] Jhankar 17 (4): 306-310.

Malik, Ramesh Chandra, and Panchanan Mohanty. 2017. "History of Odia Translations (18031936): A Bottom-Up Approach.” In History of Translation in India, edited by Tariq Khan, 33-100. Mysuru: National Translation Mission, Central Institute of Indian Languages.

Mishra, Kumudini. 1998. "Pranayini Kabya re Nilakantha ka Anuvaad Kala-Kusalata." [Nilakantha's translation skills: Discussion of Prenayani.] Konark, no. 108.

Mishra, Nilamani. (1976) 2018. "Odia Anuvaad: Sahitya O Purana." [Odia translation: Literature and Purana.] In Sanjoga Shilpa ra Sutradhaar: Odia Anuvaad Adhyayana ra Kramaparinama [Architect's craft of communication: A chronological history of the Odia translation studies], edited by Panchanan Mohanty and Ramesh Chandra Malik, 82-98. Cuttack: Friends.

Mohanty, Janakiballav. 1969. “Odia Anuvaad Sahitya.” [Odia translation literature.] Jhankar 11 (9): 883-888. 
transLogos 2020 Vol 3 Issue 1

Ganguly, Sonali, Lipika Das,

and Tanutrushna Panigrahi, pp. 46-69

An Overview of Translation Practice in Odisha:

trans Logos

A Translation Studies Journal

From Transcreation to Translation

(C) Diye Global Communications diye.com.tr|diye@diye.com.tr

Mohanty, Laxminarayan. 1971. "Odia Anuvaad Sahitya." [Odia translation literature.] Konark 6 (9).

Mohanty, Panchanan. (1997) 2018. "Bada Kathina Se Priti Paliba." [Difficulties of translation.] In Sanjoga Shilpa ra Sutradhaar: Odia Anuvaad Adhyayana ra Kramaparinama [Architect's craft of communication: A chronological history of the Odia translation studies], edited by Panchanan Mohanty and Ramesh Chandra Malik, 151-156. Cuttack: Friends.

2. 2002. "British Language Policy in 19th Century India and the Oriya Language Movement." Language Policy 1 (1): 53-73. doi:10.1023/A:1014500828789.

Mohanty, Panchanan, and Ramesh Chandra Malik, eds. 2018. Sanjoga Shilpa ra Sutradhaar: Odia Anuvaad Adhyayana ra Kramaparinama [Architect's craft of communication: A chronological history of the Odia translation studies]. Cuttack: Friends.

Mohanty, Prafulla Kumar. (2006) 2018. "Anuvaadaka ra Jantrana." [The translator's pain.] In Sanjoga Shilpa ra Sutradhaar: Odia Anuvaad Adhyayana ra Kramaparinama [Architect's craft of communication: A chronological history of the Odia translation studies], edited by Panchanan Mohanty and Ramesh Chandra Malik, 206-212. Cuttack: Friends.

Mukherjee, Sujit. 1981. Translation as Discovery and Other Essays on Indian Literature in English Translation. New Delhi: Allied.

. 2004. Translation as Recovery. Edited by Meenakshi Mukherjee. New Delhi: Pencraft International.

Nayak, Khetrabasi. (1976) 2018. "Bhasantara ra Bhasya." [Language of translation.] In Sanjoga Shilpa ra Sutradhaar: Odia Anuvaad Adhyayana ra Kramaparinama [Architect's craft of communication: A chronological history of the Odia translation studies], edited by Panchanan Mohanty and Ramesh Chandra Malik, 108-113. Cuttack: Friends.

Panda, Aditya Kumar. 2017. "Translation in Odia: A Historical Overview." In History of Translation in India, edited by Tariq Khan, 257-280. Mysuru: National Translation Mission, Central Institute of Indian Languages.

Patnaik, B. N. 2002. "Oriya Language Movement and Oriya Linguistics." International Journal of Dravidian Linguistics 31 (2): 1-16. http://home.iitk.ac.in/ patnaik/documents/oriya_move.pdf.

Pradhan, Krushnachandra. (2016) 2018. "Sampratika Samaya re Prekhyapatare Anuvaad ra Samasya O Gurutwa." [Importance and challenges of translation in the contemporary time.] In Sanjoga Shilpa ra Sutradhaar: Odia Anuvaad Adhyayana ra Kramaparinama [Architect's craft of communication: A chronological history of the Odia translation 
transLogos 2020 Vol 3 Issue 1

Ganguly, Sonali, Lipika Das,

and Tanutrushna Panigrahi, pp. 46-69

An Overview of Translation Practice in Odisha:

trans Logos

A Translation Studies Journal

From Transcreation to Translation

(C) Diye Global Communications diye.com.tr|diye@diye.com.tr

studies], edited by Panchanan Mohanty and Ramesh Chandra Malik, 245-251. Cuttack: Friends.

Pradhan, Saratchandra. (1959) 2018. "Odia Sahitya re Anuvaad." [Translation in Odia literature.] In Sanjoga Shilpa ra Sutradhaar: Odia Anuvaad Adhyayana ra Kramaparinama [Architect's craft of communication: A chronological history of the Odia translation studies], edited by Panchanan Mohanty and Ramesh Chandra Malik, 18-22. Cuttack: Friends.

Ramakrishna, Shantha. 2002. "Cultural Transmission through Translation: An Indian Perspective." In Changing the Terms: Translating in the Postcolonial Era, edited by Sherry Simon and Paul St-Pierre, 87-100. Hyderabad: Orient Longman.

Rath, Mrutyunjaya. (1921) 2018. “Anuvaad.” [Translation.] In Sanjoga Shilpa ra Sutradhaar: Odia Anuvaad Adhyayana ra Kramaparinama [Architect's craft of communication: A chronological history of the Odia translation studies], edited by Panchanan Mohanty and Ramesh Chandra Malik, 1-9. Cuttack: Friends.

Sahu, Abhinnachandra. (1962) 2018. "Anuvaad O amara Anuvaadaka." [Translation and our translators.] In Sanjoga Shilpa ra Sutradhaar: Odia Anuvaad Adhyayana ra Kramaparinama [Architect's craft of communication: A chronological history of the Odia translation studies], edited by Panchanan Mohanty and Ramesh Chandra Malik, 23-30. Cuttack: Friends.

Tripathy, Kunjabihari. (1984) 2018. "Nilakantha ka Kabyakruti Dasa Nayaka: Eka Adhyayana." [A study of Nilakantha's translation of Dasa Nayaka.] In Sanjoga Shilpa ra Sutradhaar: Odia Anuvaad Adhyayana ra Kramaparinama [Architect's craft of communication: A chronological history of the Odia translation studies], edited by Panchanan Mohanty and Ramesh Chandra Malik, 129-137. Cuttack: Friends.

Trivedi, Harish. 2004. "Introduction." In Translation as Recovery, edited by Meenakshi Mukherjee, 11-20. New Delhi: Pencraft International.

2007. "Colonial Influence, Postcolonial Intertextuality: Western Literature and Indian Literature." Forum for Modern Language Studies 43 (2): 121-133. doi:10.1093/fmls/cqm006. 